\title{
Pontomedullary Glutamate Receptors Mediating Locomotion and Muscle Tone Suppression
}

\author{
Y. Y. Lai and J. M. Siegel \\ VAMC, Sepulveda, California 91343 and Department of Psychiatry and Brain Research Institute, School of Medicine, \\ University of California, Los Angeles, California 90024
}

Microinjection of NMDA and non-NMDA agonists into the same sites in pontomedullary motor "inhibitory" areas of decerebrate animals produced opposite effects on muscle tone. Microinjection of non-NMDA agonists into peri-locus coeruleus alpha (peri-LC $\alpha$ ) and nucleus magnocellularis (NMC) suppressed muscle tone, while injection of NMDA agonists at the same sites increased muscle tone and produced locomotion. The latency, duration, and magnitude of muscle tone change after both NMDA and non-NMDA agonist injections were dose dependent. Increased muscle tone and locomotor effects were blocked by NMDA antagonists, and muscle tone suppression effects were blocked by non-NMDA antagonists. We conclude that pontomedullary non-NMDA receptors mediate muscle tone suppression, and that NMDA receptors mediate locomotion and muscle tone facilitation. Activation of both NMDA and non-NMDA pontomedullary receptors by glutamate release in REM sleep can explain the combination of motor activation and loss of muscle tone that characterizes this state. In the waking animal, the co-localization of these mechanisms may facilitate the coordination of locomotion with postural adjustments.

REM sleep is characterized by a complete suppression of muscle tone, combined with a seemingly "paradoxical" central motor activation. Muscle tone suppression requires the integrity of the dorsolateral pons (Jouvet and Delorme, 1965; Hendricks et al., 1982; Chase, 1983; Amini-Sereshki and Morrison, 1986) and medial medulla (Schenkel and Siegel, 1989). Damage to these regions produces REM sleep without atonia, during which elaborate motor activities are expressed in a state with all of the other characteristics of REM sleep. Infusion of cholinergic agonists into the dorsolateral pons induces atonia and other signs of REM sleep (George et al., 1964; van Dongen et al., 1978; Baghdoyan et al., 1984; Katayama et al., 1984; Shiromani et al., 1986).

Electrical stimulation of the nucleus magnocellularis (NMC) and paramedianus of the medial medulla and of the dorsolateral pontine tegumentum produces suppression of muscle tone (Lai et al., 1987; Lai and Siegel, 1990a). Recently, we reported that repetitive electrical stimulation of these sites transformed the

Received Feb. 11, 1991; revised Apr. 4, 1991; accepted Apr. 25, 1991.

This work was supported by the Medical Research Service of the Veterans Administration and by U.S. Public Health Service Grants HL41370, NS14610, and MH43811.

Correspondence should be addressed to Y. Y. Lai, Neurobiology Research 151A3, VAMC, Sepulveda, CA 91343.

Copyright (C) 1991 Society for Neuroscience $0270-6474 / 91 / 112931-07 \$ 03.00 / 0$ atonia response into a locomotor response (Lai and Siegel, 1990a). The atonia response in the peri-locus coeruleus region and in the NMC of the medial medulla is not mediated by fibers of passage since it can be induced by activation of non-NMDA glutamate receptors (Lai and Siegel, 1988). In the present study, we sought to determine if the locomotor response could be triggered by chemical stimulation of the same sites and to identify the receptor responsible for this effect.

\section{Materials and Methods}

Experiments were performed on 17 unanesthetized, pre-collicular-postmammillary decerebrate cats of either sex, weighing $2.2-4.5 \mathrm{~kg}$. Surgical procedures were described previously (Lai and Siegel, 1990b). Core temperature was maintained at $38 \pm 1^{\circ} \mathrm{C}$ by a thermoregulated heating pad. Blood pressure was monitored, and mean arterial blood pressure remained over $80 \mathrm{~mm} \mathrm{Hg}$ in all preparations. Electromyograms were recorded from occipitoscapularis, splenius, and biventer cervices of the neck and triceps brachii muscles of the forelimb. The areas producing bilateral inhibition of muscle tone were identified by electrical stimulation (500 msec trains with $100 \mathrm{~Hz}, 0.2 \mathrm{msec}, 20-70 \mu \mathrm{A}$ rectangular cathodal pulses) through a stainless-steel monopolar microelectrode with tip size of 0.01 inch (model 5710, A-M Systems, Inc.). The region from $\mathrm{P} 1$ to $\mathrm{P} 4,1-4 \mathrm{~mm}$ from the midline and $0-6.0 \mathrm{~mm}$ dorsoventrally in the pons, and from P8 to P11, $1 \mathrm{~mm}$ from the midline and from -7.0 to -9.0 dorsoventrally in the medulla (Berman, 1968) was explored in $0.5 \mathrm{~mm}$ increments. Once the inhibitory area was identified, $0.5 \mu 1$ of each of several glutamate agonists at varying concentrations was microinjected over a $2 \mathrm{~min}$ period through a stereotaxically positioned 1 $\mu$ l Hamilton microsyringe (7001, 26S-gauge). Antagonist experiments were performed by injecting antagonist followed by agonist after a 5 min interval. Agonist was microinjected again after 2 or $10 \mathrm{hr}$ to confirm the baseline response. Recovery of agonist effects occurred in every case. The interval between two experiments at the same site was a minimum of $2 \mathrm{hr}$. In eight sites, only one non-NMDA agonist was injected. In 15 sites, two or three non-NMDA agonists were injected. In eight sites, only NMDA agonists were injected. In five sites, both NMDA and nonNMDA agonists were injected. At two of these sites the NMDA agonists were injected first, while in three, non-NMDA agonists were injected first. Duration of the inhibitory effects was calculated from the point of suppression of muscle tone below $50 \%$ of the preinjection level and recovery, the point at which tone returned to above $50 \%$ of baseline levels. Duration of excitatory effects was calculated from the time at which muscle tone increased $50 \%$ above preinjection level or at which rhythmic movement began.

All chemicals except 6-cyano-7-nitroquinoxaline-2,3-dione (CNQX) and 6,7-dinitroquinoxaline-2,3-dione (DNQX) were dissolved in Ringer's saline solution, $\mathrm{pH}$ adjusted to 7.2-7.4. CNQX and DNQX were dissolved in $45 \%$ aqueous 2 -hydroxypropyl- $\beta$-cyclodextrin and then diluted with Ringer's saline. The injection sites were verified by electrolytic iron deposits revealed by the ferrocyanide reaction.

\section{Results}

Electrical stimulation-induced muscle tone suppression could be found from $\mathrm{P} 2$ to $\mathrm{P} 4,2-3.5 \mathrm{~mm}$ from midline and $\mathrm{H}-3.5$ to -5 in the pons, and from P8 to P11, $1 \mathrm{~mm}$ from midline and 

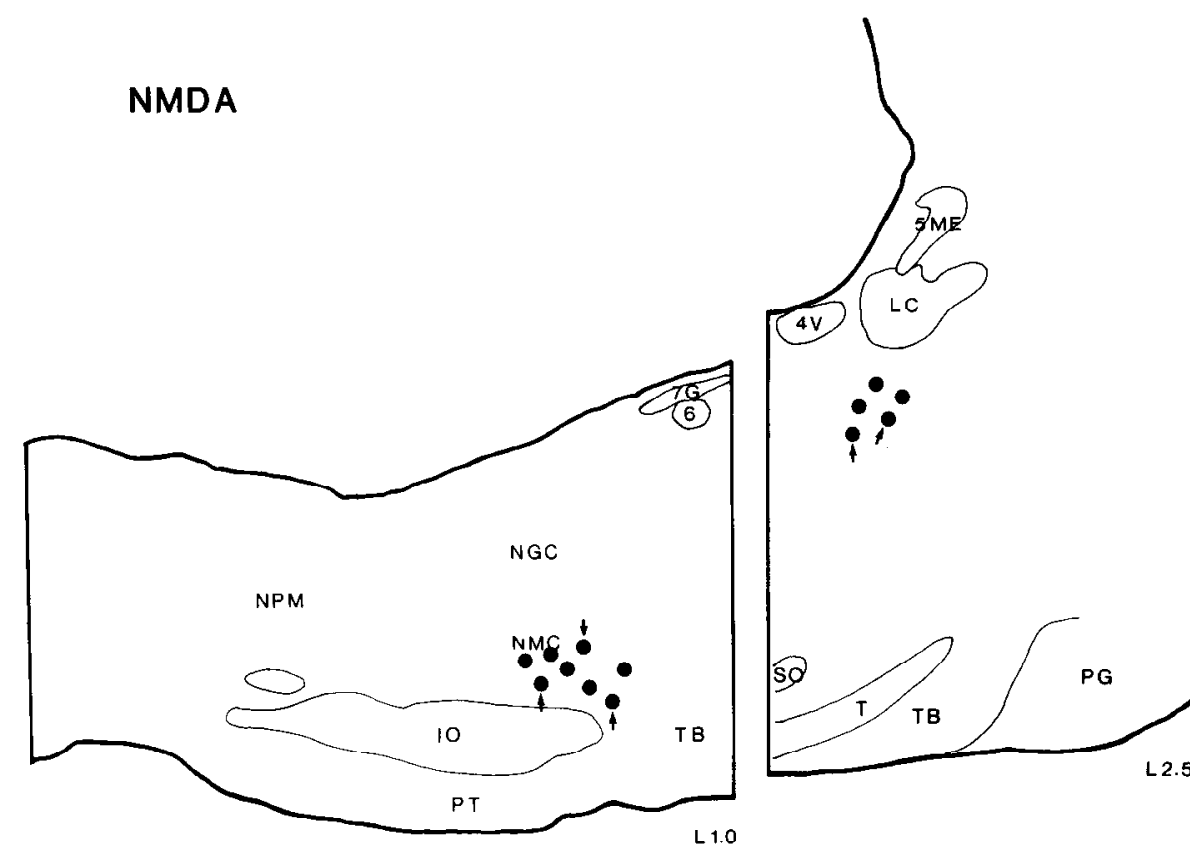

Figure 1. Schematic mapping of NMDA and non-NMDA agonist injection sites. Data was reconstructed from 17 cat experiments. Injection sites were located by electrical stimulation-produced atonia. Chemical stimulation at all of these sites produced changes in muscle activity. NMDA microinjection facilitated muscle tone and/or stepping-like activity, while non-NMDA agonists produced muscle suppression or atonia. The sites receiving both NMDA and non-NMDA agonist injections are indicated with arrows. $4 \mathrm{~V}$, forth ventricle; $5 M E$, mesencephalic trigeminal nucleus; 6 , abducens nucleus; $7 G$, genu of the facial nerve; $I O$, inferior olivary nucleus; $L C$, locus coeruleus nucleus; $N G C$, nucleus gigantocellularis; $N M C$, nucleus magnocellularis; $N P M$, nucleus paramedianus; $P G$, pontine gray; $P T$, pyramidal tract; $S O$, superior olivary nucleus; $T$, nucleus of the trapezoid body; $T B$, trapezoid body.

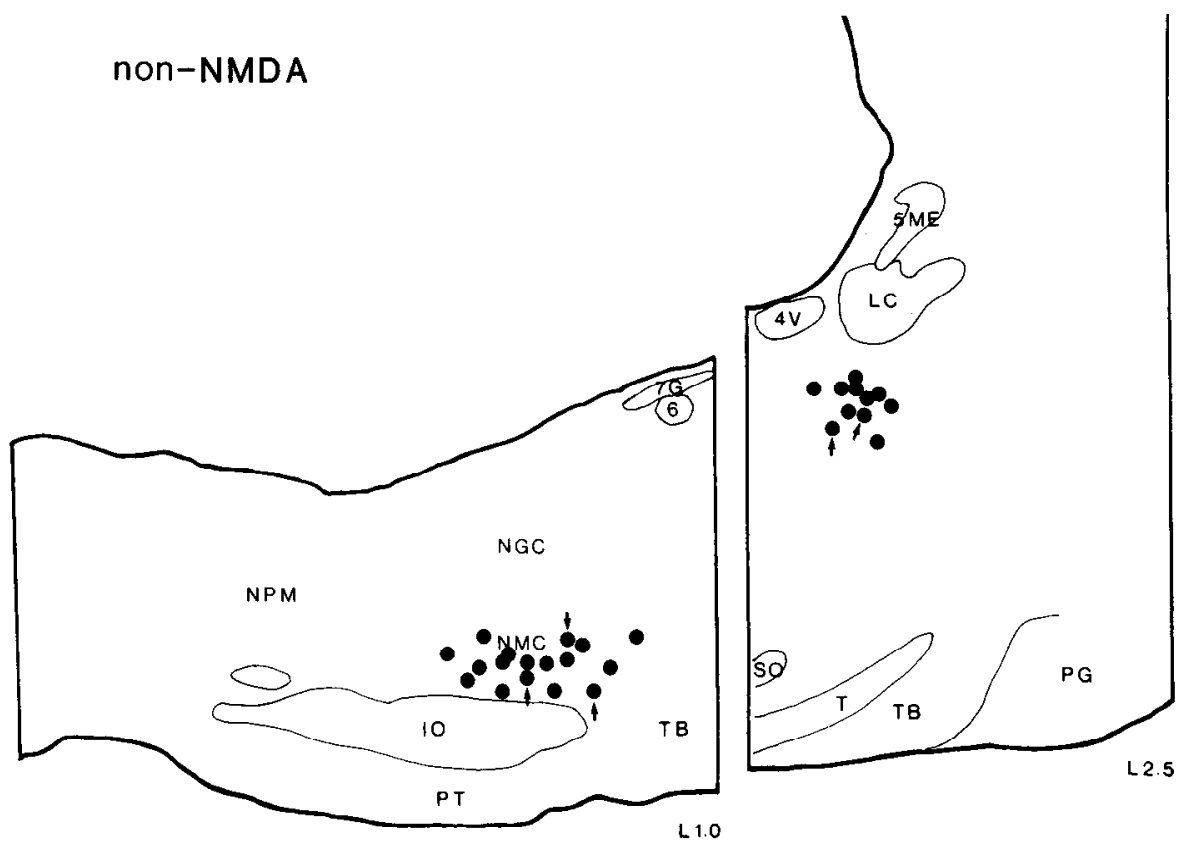

H-7.5 to -9 in the medial medulla. We utilized sites that produced muscle tone suppression at current levels below $40 \mu \mathrm{A}$ for our microinjection studies. NMDA injection into both pontine and NMC "inhibitory" areas, previously identified by their response to electrical stimulation (Lai and Siegel, 1988), produced a facilitation of muscle tone and/or stepping-like activity, at all 13 sites tested (Fig. 1). With higher levels of preinjection muscle tone (splenius muscle tone, $>25 \mu \mathrm{V}$ ), NMDA injection $(6.8 \mathrm{~mm})$ produced tonically increased tone only (Fig. 2), but with lower preinjection muscle tone levels, locomotion was induced by NMDA (Fig. 3). Repeated injections at the same site produced the same effects; up to five injections of NMDA were observed to produce facilitation of muscle tone with comparable latency and duration. Microscopic analyses of injection sites did not reveal any evidence of gliosis or cell loss, indicating that the cytotoxic effects of glutamate agonists were not present at the doses employed.

The latency and duration of the NMDA-induced facilitatory 


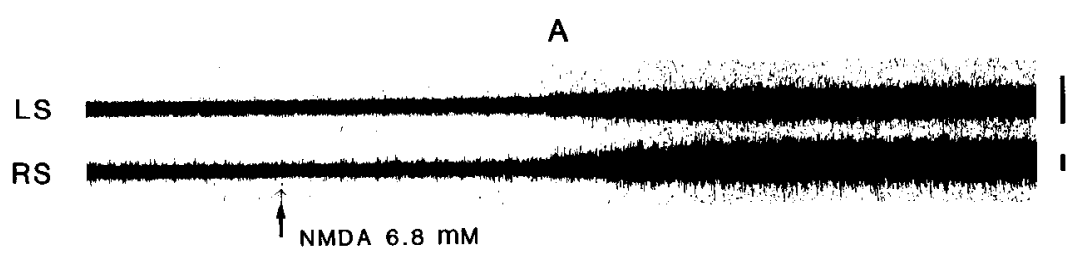

B

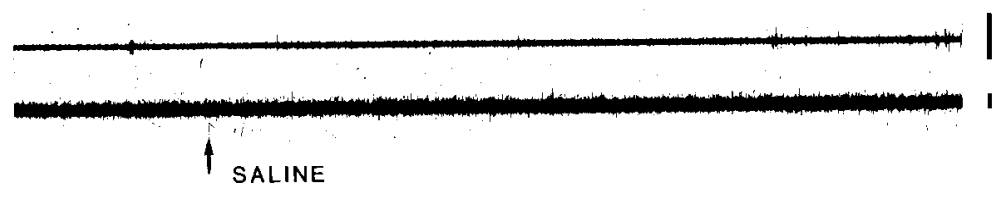

C

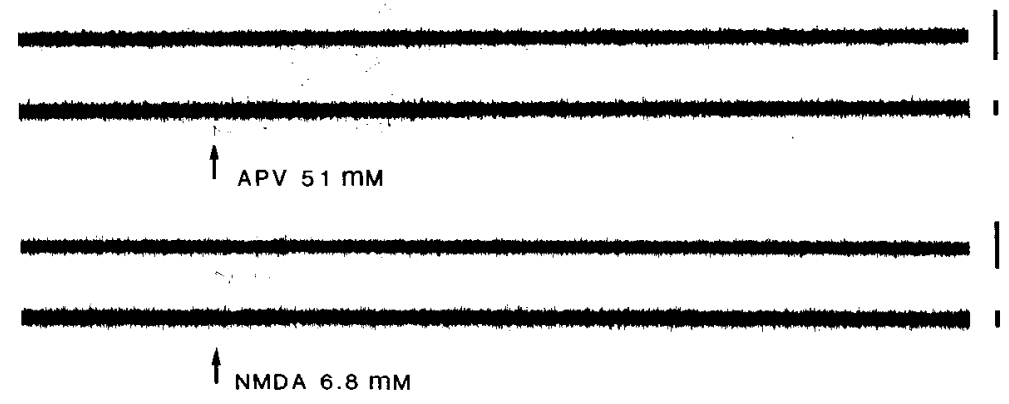

D

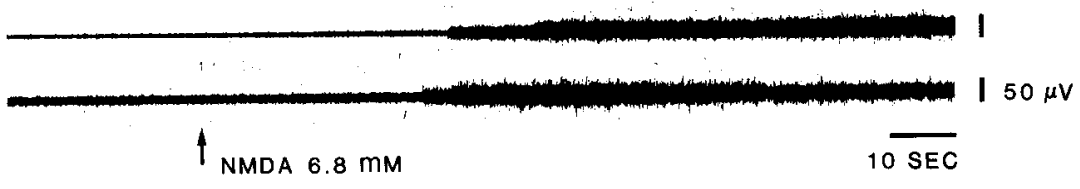

Figure 2. Muscle facilitation produced by microinjection of NMDA and blocked by antagonist injection. $A$, Microinjection of NMDA into NMC induced muscle facilitation when the basal neck muscle tone was above $25 \mu \mathrm{V}$. $B$, Vehicle saline injection did not produce any change of muscle activity. $C$, Specific NMDA antagonist APV injected into the same site $5 \mathrm{~min}$ before the NMDA, completely blocked the effect of NMDA on muscle activity. $D$, One hour after antagonist experiment, NMDA microinjection again produced muscle facilitation. $L S$ and $R S$, left and right splenius, respectively. effect on muscle activity was dose dependent (Fig. 4), but the direction of effect was the same from threshold levels up to the maximum dosages employed; NMDA always produced increased muscle tone or locomotion, and non-NMDA agonists always produced muscle tone suppression (Figs. 3, 5). The latency, defined as the time from the start of injection to the onset of muscle activity change, was $24 \pm 11.3 \mathrm{sec}$ (range, 12-40 sec) at a $6.8 \mathrm{~mm}$ concentration. The facilitation of muscle tone or locomotion lasted for $3.0 \pm 0.67 \mathrm{~min}$ (range, $2.2-4.2 \mathrm{~min}$ ) at $6.8 \mathrm{~mm}$. This NMDA-induced muscle facilitation and/or locomotion was blocked by prior microinjection of $51 \mathrm{mM}$ of $\mathrm{D}, \mathrm{L}-2$ amino-5-phosphonovaleric acid (APV; $n=7$; Fig. 1), a specific NMDA antagonist. NMDA-induced muscle facilitation recovered by $3 \mathrm{hr}$ after antagonist injection (Fig. 2). Vehicle Ringer's saline microinjection produced no effect on either muscle tone or locomotion (Fig. 2).

In contrast to the NMDA effect, non-NMDA agonists, kainate (KA), quisqualate (QA), and willardine (WL) microinjected into the same sites or into nearby inhibitory areas (Fig. 1), produced bilateral muscle tone suppression or atonia, at 42 of 44 inhibitory sites tested (Fig. 6). This non-NMDA-induced muscle tone suppression was also dose dependent (Fig. 4). The latency of muscle tone suppression induced by non-NMDA injection was
$20.5 \pm 9.7 \mathrm{sec}$ after $10 \mathrm{~mm}$ QA, $28.5 \pm 17.1 \mathrm{sec}$ after $280 \mu \mathrm{M}$ $\mathrm{KA}$, and $12.5 \pm 13.6 \mathrm{sec}$ after $100 \mu \mathrm{M}$ WL (see Fig. 4 for $N$ values). At the above-listed concentrations, the average duration of muscle tone suppression was $13.3 \pm 3.0 \mathrm{~min}$ after QA, $4.5 \pm 1.0 \mathrm{~min}$ after $\mathrm{KA}$, and $6.1 \pm 3.2 \mathrm{~min}$ after WL. Specific non-NMDA antagonists CNQX $(10 \mu \mathrm{M})$ and DNQX $(10 \mu \mathrm{M})$ attenuated or completely blocked the non-NMDA agonists' effect on muscle tone suppression (Fig. 7). Since the blockade of the NMDA effect by the quinoxalinediones lasted $>5 \mathrm{hr}$, similar to previous reports of the long-duration effects of these compounds (Anderson et al., 1989), only four experiments were done with CNQX and DNQX. Antagonist experiments were also done with L-glutamic acid diethyl ester (GDEE; $0.2 \mathrm{M}$ ) and gamma-D-glutamylglycine (DGG; $10 \mathrm{~mm})$. Both GDEE $(n=19)$ and DGG $(n=8)$ were found to antagonize the effect of nonNMDA agonists on muscle activity, and these effects lasted $<15$ min, allowing multiple tests in a single experiment.

\section{Discussion}

Microinjection of NMDA into the NMC of the medial medulla has been reported to produce locomotion (Atsuta et al., 1989; Kinjo et al., 1990) in decerebrate cats and rats placed on a moving treadmill. Our present studies show that NMDA is 


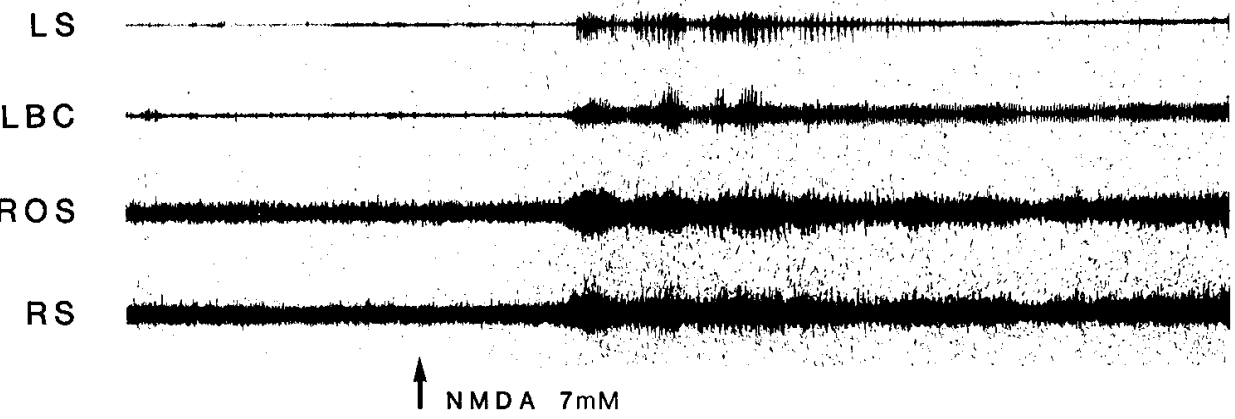

Figure 3. Increased muscle tone with locomotion, produced by NMDA injection. One-half microliter of $7 \mathrm{~mm}$ NMDA microinjected into pontine inhibitory area not only produced an increase in tone but also induced stepping-like activity. The latency and duration were $17 \mathrm{sec}$ and $3 \mathrm{~min}$, respectively. $L O S$ and $R O S$, left and right occipitoscapularis, respectively; $L B C$ : left biventer cervicis.

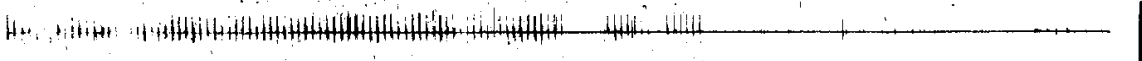

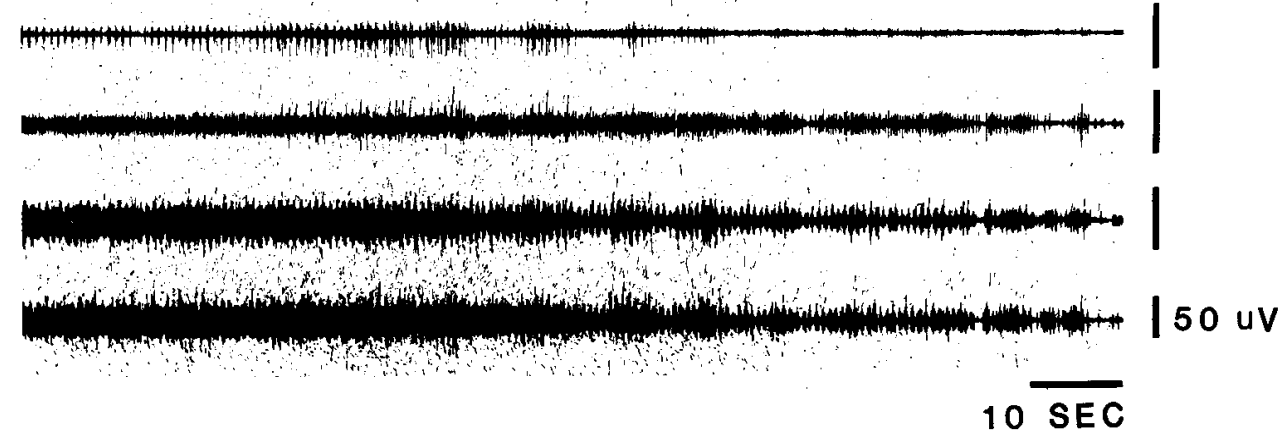

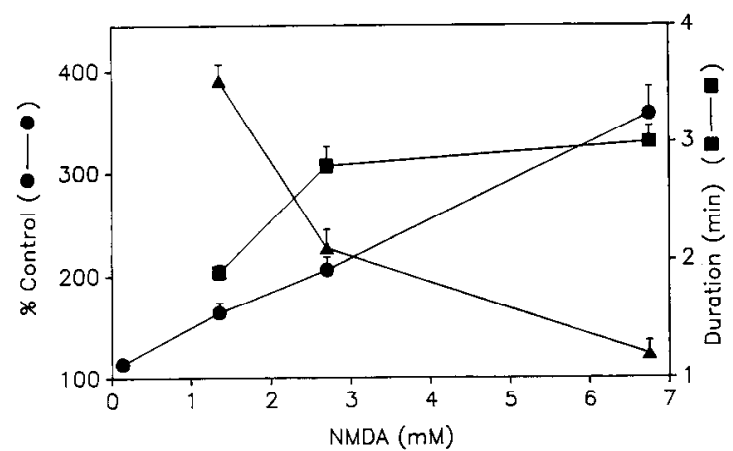

$\int_{-60}^{80}$

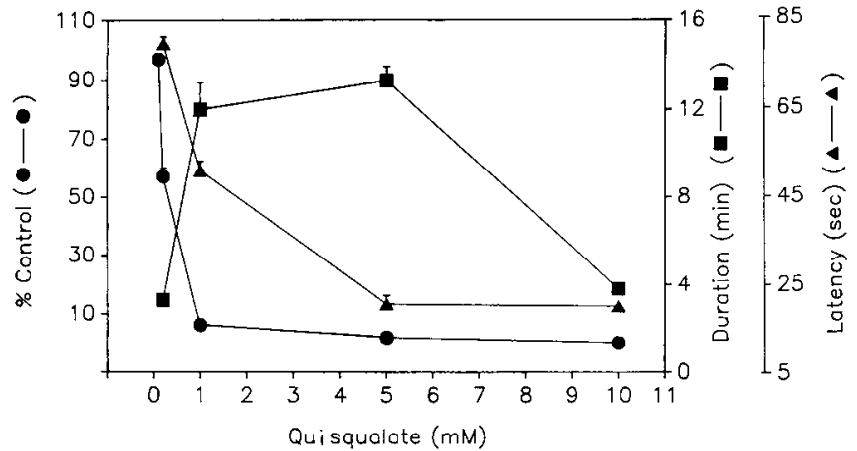

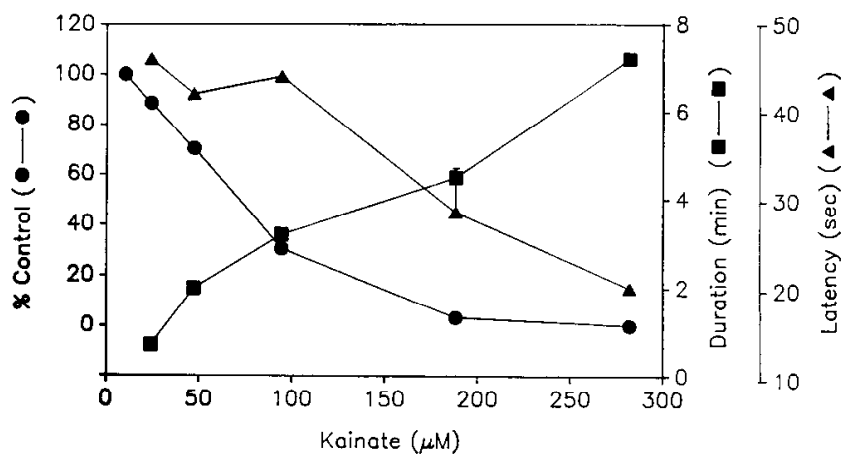

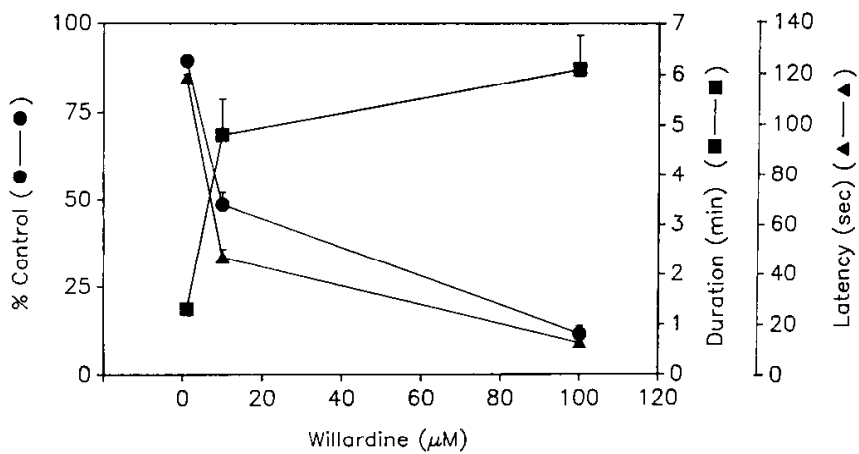

Figure 4. Dose-dependent effect of NMDA and non-NMDA agonists on muscle tone. EMG magnitude (\% control) was calculated with reference to integrated EMG amplitude in 2 min baseline period. Each point except the $10 \mu \mathrm{m} \mathrm{KA}$ injection (one injection) was based on the mean activity of the six recorded muscles in four experiments. Points represent mean \pm SE. The concentrations of chemicals were as follows: NMDA: 0.135 , $1.35,2.7$, and $6.8 \mathrm{mM}$; KA: $10,23.5,47,94,188$, and $282 \mu \mathrm{M} ; \mathrm{QA}: 0.1,1,5$, and $10 \mathrm{mM}$; WL; 1, 10 , and $100 \mu \mathrm{M}$. 
A
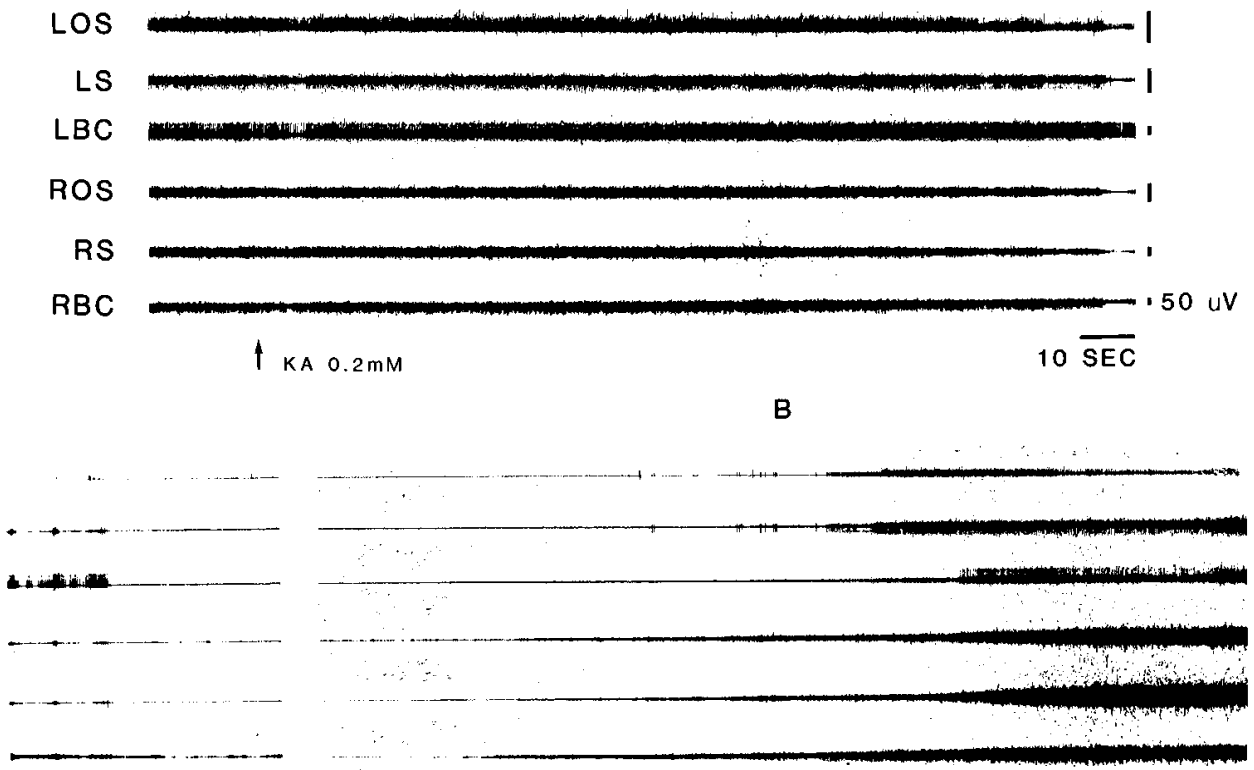

Figure 5. Muscle suppression induced by KA injection. 'The injection site was the same as in Figure 3. $R B C$, right biventer cervicis. See Figure 3 for other abbreviations. Sample $B$, showing recovery of tone, was taken 8 min after sample $A$. effective in producing locomotion in both medial pons and NMC even without treadmill stimulation. The sites where NMDA is effective are identical to those where electrical stimulation, glutamate (Lai and Siegel, 1900), and non-NMDA agonist microinjections produce muscle tone suppression. The opposite effects of NMDA and non-NMDA agonists lead us to hypothesize that muscle tone suppression and facilitation/locomotion are elicited from the same sites but through different receptors.
NMDA and non-NMDA receptors may be present in varying proportions on adjacent neurons. Electrophysiological studies have shown that REM sleep- and motor behavior-related neurons are intermingled in pontomedullary areas (Siegel and McGinty, 1977; Siegel et al., 1979, 1983; Chandler et al., 1980). These neuronal subpopulations can be selectively activated as a function of sleep-waking state. Stimulation of pontine reticular areas produce EPSPs during wakefulness and quiet sleep and
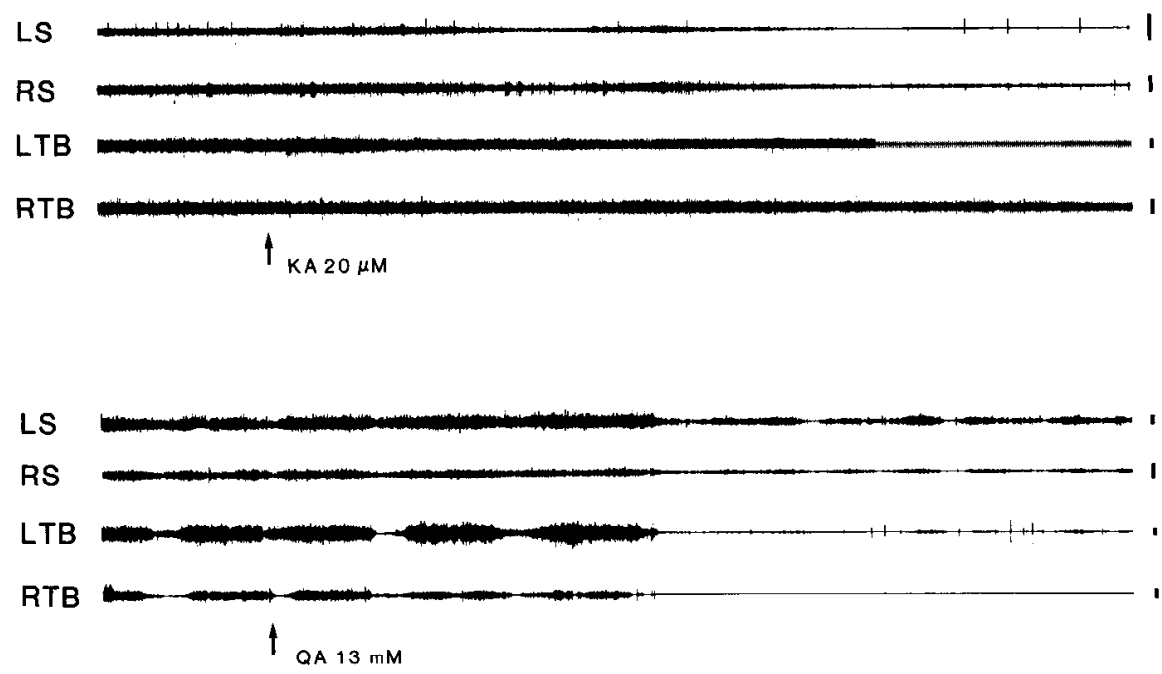

LS

RS

LTB

RTB

S

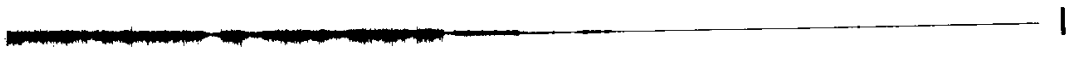

$(4$

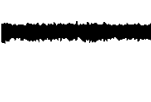

Figure 6. Atonia induced by nonNMDA agonist microinjection into medulla. QA and WL were injected into the same site of the same cat, while KA was injected in the medulla of a different cat. All three non-NMDA agonists produced muscle suppression. $L T B$ and $R T B$, left and right triceps brachii, respectively. 


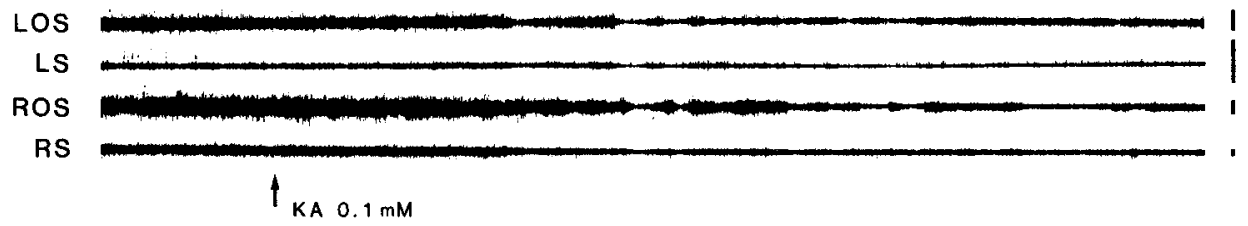

Figure 7. DNQX blocked KA-induced muscle suppression in the NMC of the medulla. Top, Microinjection of KA produced suppression of the neck musclc activity, bilatcrally. Middle, Specific non-NMDA antagonist, DNQX, produced no effect on muscle activity. Bottom, Application of KA 5 min after DNQX injection did not induce muscle suppression and actually produced a small increase in tone in LOS and $L S$.
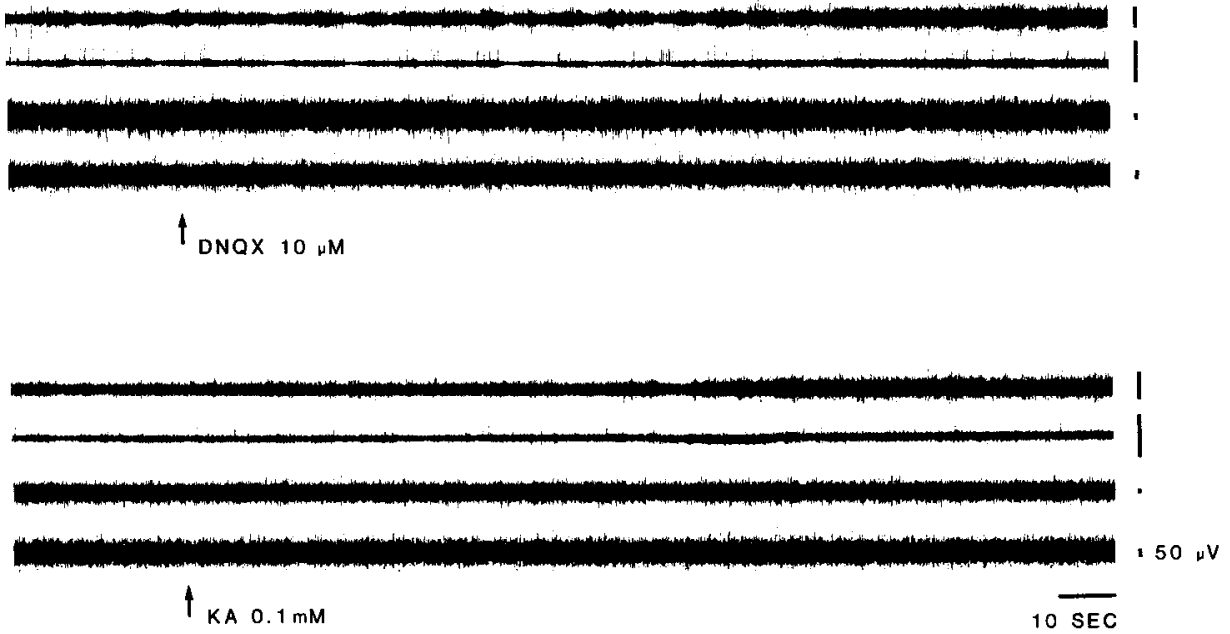

IPSPs during REM sleep in masseter and lumbar motoneurons (Fung et al., 1982). Peterson and collaborators (Peterson et al., 1978,1979 ) have shown both inhibitory and excitatory reticulospinal effects from electrical stimulation of the medulla. Previous studies from our laboratory have shown that glutamate injections into the pontomedullary inhibitory areas produced muscle tone suppression only (Lai and Siegel, 1988), presumably because the L-form of glutamate acts mainly at non-NMDA receptors (Davies et al., 1982).

The opposite effects of NMDA and non-NMDA receptors can explain the pattern of motor activity seen in REM sleep. We hypothesize that glutamate release during REM sleep produces activation of non-NMDA receptors in pontomedullary regions producing muscle atonia. Membrane depolarization resulting from non-NMDA activity in turn facilitates response to NMDA receptor activation (Nowak et al., 1984; Klein et al., 1989 ) in neuronal populations responsible for phasic motor excitation. This results in the characteristic pattern of twitches superimposed on a background of muscle atonia seen in REM sleep.

The REM sleep behavior disorder is a disease in which extensive motor activity occurs during REM sleep (Schenck et al., 1986). In some cases, discrete lesions in the pontine inhibitory areas have been identified (Culebras and Moore, 1989). However, in most cases, no overt lesion is detectable (Schenck et al., 1986), although "soft" neurological signs are often present. We hypothesize that a diffuse degeneration within the brainstem may cause the ratio of NMDA and non-NMDA receptors, or of neurons containing these receptors to shift. We hypothesize that this process causes the NMDA response to become more prominent, resulting in increased motor activity in REM sleep.

The background excitability of the motor system has previously been shown to modulate the locomotor response to brain stimulation. Locomotion can be elicited by pontine ventral tegmentum stimulation only when the basal muscle activity is at an "optimal" intermediate level (Mori et al., 1986). Stimulation at "locomotor" sites is ineffective when very high or low (atonia) muscle tone levels are present at stimulation onset (Mori et al., 1986). We have seen a similar phenomenon with NMDA injection in the present studies. NMDA agonists produce locomotion only when preinjection muscle tone is at an intermediate level. The co-localization and interaction of pontine and medullary glutamate atonia and rhythmic motor mechanisms may contribute to the coordination of postural tone and locomotion in waking.

The pontine area in which NMDA and non-NMDA agonists induced opposite effects has been shown to produce REM sleeplike activity with carbachol infusion in intact animals (George et al., 1964; van Dongen et al., 1978; Baghdoyan et al., 1984; Shiromani et al., 1986). ACh and glutamate are co-localized in some pedunculopontine nucleus neurons (Clements and Grant, 1990). We hypothesize that neurons containing glutamate, $\mathrm{ACh}$, or both of these transmitters project to the ACh-Glu receptive area that we have explored in the medial pons. The co-release of these transmitters may be required for the full expression of REM sleep phenomena.

\section{References}

Amini-Sereshki L, Morrison AR (1986) Effects of pontine tegmental lesions that induce paradoxical sleep without atonia on thermoregulation in cats during wakefulness. Brain Res 384:23-29.

Andreasen M, Lambert JDC, Jensen MS (1989) Effects of new non$N$-methyl-D-aspartate antagonists on synaptic transmission in the in vitro rat hippocampus. J Physiol (Lond) 414:317-336.

Atsuta Y, Skinner RD, Garcia-Rill E (1989) NMDA induced locomotion in rat and cat. Soc Neurosci Abstr 15:391.

Baghdoyan HA, Rodrigo-Angula ML, McCarley RW, Hobson JA (1984) Site-specific enhancement and suppression of desynchronized sleep signs following cholinergic stimulation of three brainstem regions. Brain Res 306:39-52.

Berman AL (1968) The brain stem of the cat. Madison: Univ Wisconsin Press. 
Chandler SH, Nakamura Y, Chase MH (1980) Intracellular analysis of synaptic potentials induced in trigeminal jaw-closer motoneurons by pontomesencephalic reticular stimulation during sleep and wakefulncss. J Neurophysiol 44:372-382.

Chase MH (1983) Synaptic mechanisms and circuitry involved in motoneuron control during sleep. Int Rev Neurobiol 24:213-258.

Clements JR, Grant SJ (1990) Glutamate and acetylcholine are colocalized in the laterodorsal tegmental and pedunculopontine nuclei. Soc Neurosci Abstr 16:1189.

Culebras A, Moore JT (1989) Magnetic resonance findings in REM sleep behavior disorder. Neurology 39:1519-1523.

Davies J, Evans RH, Jones AW, Smith DAS, Watkins JC (1982) Differential activation and blockade of excitatory amino acid receptors in the mammalian and amphibian central nervous systems. Comp Biochem Physiol 72C:211-224.

Fung SJ, Boxer PA, Morales FR, Chase MH (1982) Hyperpolarizing membrane responses induced in lumbar motoneurons by stimulation of the nucleus reticularis pontis oralis during active sleep. Brain Res 248:267-273.

George R, Haslett WL, Jenden DJ (1964) A cholinergic mechanism in the brainstem reticular formation: induction of paradoxical sleep. Int J Neuropharmacol 3:541-552.

Hendricks JC, Morrison AR, Mann GL (1982) Different behaviors during paradoxical sleep without atonia depend on pontine lesion site. Brain Res 239:81-105.

Jouvet M, Delorme F (1965) Locus coeruleus et sommeil paradoxal. CR Soc Biol 159:895-899.

Katayama Y, DeWitt DS, Becker DP, Hayes RL (1984) Behavioral evidence for cholinoceptive pontine inhibitory area: descending control of spinal motor output and sensory input. Brain Res 296:241262.

Kinjo N, Atsuta Y, Webber M, Kyle R, Skinner RD, Garcia-Rill E (1990) Medioventral medulla-induced locomotion. Brain Res Bull 24:509-516.

Klein WL, Sullivan J, Skorupa A, Aguilar JS (1989) Plasticity of neuronal receptors. FASEBS J 3:2132-2140.

Lai YY, Siegel JM (1988) Medullary regions mediating atonia. J Neurosci 8:4790-4796.

Lai YY, Siegel JM (1990a) Muscle tone suppression and stepping produced by stimulation of midbrain and rostral pontine reticular formation. J Neurosci 10:2727-2734.

Lai YY, Siegel JM (1990b) Cardiovascular and muscle tone changes produced by microinjection of cholinergic and glutamatergic agonists in dorsolateral pons and medial medulla. Brain Res 514:27-36.

Lai YY, Siegel JM, Wilson WJ (1987) Effect of blood pressure on changes in muscle tone produced by stimulation of the medial medulla. Am J Physiol 252:H1249-H1257.

Mori S, Ohta Y, Sakamoto T, Nonaka S (1986) Excitability levelsetting mechanisms in the pons: their behavioral support in decerebrate, reflex standing and freely moving, intact cats. Brain Dev 8: $408-415$.

Nowak L, Bregestovski P, Ascher P, Herbet A, Prochiantz A (1984) Magnesium gates glutamate-activated channels in mouse central neurones. Nature 307:462-465.

Peterson BW, Pitts NG, Fukushima K, Mackel R (1978) Reticulospinal excitation and inhibition of neck motoneurons. Exp Brain Res 32:471-489.

Peterson BW, Pitts NG, Fukushima K (1979) Reticulospinal connections with limb and axial motoneurons. Exp Brain Res 36:1-20.

Schenck CH, Bundlie SR, Ettinger MG, Mahowald MW (1986) Chronic behavioral disorders of human REM sleep: a new category of parasomnia. Sleep 9:293-308.

Schenkel E, Siegel JM (1989) REM sleep without atonia after lesions of the medial medulla. Neurosci Lett 98:159-165.

Shiromani PJ, Siegel JM, Tomaszewski KS, McGinty DJ (1986) Alterations in blood pressure and REM sleep after pontine carbachol microinfusion. Exp Neurol 91:285-292.

Sicgel JM, McGinty DJ (1977) Pontine reticular formation neurons: relationship of discharge to motor activity. Science 196:678-680.

Siegel JM, Tomaszewski KS (1983) Behavioral organization of reticular formation: studies in the unrestrained cat. I. Cells related to axial limb, eye, and other movements. J Neurophysiol 50:696-716.

Siegel JM, Wheeler RL, McGinty DJ (1979) Activity of medullary reticular formation neurons in the unrestrained cat during waking and sleep. Brain Res 179:49-60.

van Dongen PAM, Broekkamp CLE, Cools AR (1978) Atonia after carbachol microinjections near the locus coeruleus in cats. Pharmacol Biochem Behav 8:527-532. 